\title{
Silicon probing tips coated with protective aluminum oxide thin films for fast tactile cantilever sensors
}

\author{
$\underline{\text { Hutomo Suryo Wasisto }}^{1,2,{ }^{*}}$, Feng Y u $^{1}$, Lutz Doering ${ }^{3}$, Stefan Völlmeke ${ }^{4}$, Manal Ali Deeb ${ }^{1}$, Uwe Brand ${ }^{3}$, \\ Andrey Bakin ${ }^{1,2}$, Andreas Waag ${ }^{1,2}$, Erwin Peiner ${ }^{1,2}$ \\ ${ }^{1}$ Institute of Semiconductor Technology, TU Braunschweig, Braunschweig, Germany \\ ${ }^{2}$ Laboratory of Emerging Nanometrology, Braunschweig, Germany \\ ${ }^{3}$ Department 5.1 Surface Metrology, Physikalisch-Technische Bundesanstalt, Braunschweig, Germany \\ ${ }^{4}$ CiS Forschungsinstitut für Mikrosensorik und Photovoltaik GmbH, Erfurt, Germany \\ "Corresponding e-mail address: h.wasisto@tu-bs.de
}

\begin{abstract}
:
Silicon microprobe tips are fabricated and integrated with piezoresistive cantilever sensors for fast surface roughness scanning systems. A combination of wet and inductively coupled plasma (ICP) cryogenic dry etching processes is employed to create high-aspect-ratio tips. For the wear-resistant tip coatings, atomic-layer deposition (ALD) technique is applied to deposit conformal $\sim 14 \mathrm{~nm}$ thick aluminum oxide $\left(\mathrm{Al}_{2} \mathrm{O}_{3}\right)$ layers using a binary reaction sequence in low thermal process with precursors of trimethyl aluminum (TMA) and water $\left(\mathrm{H}_{2} \mathrm{O}\right)$. From the preliminary friction and wear data, the developed silicon cantilever sensor has been successfully used in 100 fast scanning measurements along 5-mm-long surface traces on a standard artifact with a speed of $15 \mathrm{~mm} / \mathrm{s}$ and forces of $60-100 \mu \mathrm{N}$. These tactile sensors are targeted for use in high-aspect-ratio microform metrology.
\end{abstract}

Key words: silicon microprobe tips, piezoresistive cantilever sensors, fast surface roughness scanning systems, atomic-layer deposition (ALD), high-aspect-ratio microform metrology.

\section{Introduction}

The production and surface quality assurance of microsystem components at high throughput are still challenging in many industries, especially for high-aspect-ratio structures that require new techniques for their developments (e.g., micro gears or fuel injection nozzles in diesel engines, micro channels in fluidic devices, and micro mirrors in optical switches) [1]. To overcome this issue, tactile sensors have been used as an alternative approach for non-destructive evaluation (NDE). However, most surface measuring systems for deep narrow microholes (e.g., those based on optical fiber probes) still do not specify scanning speed [2]. From our previous studies, piezoresistive cantilever sensors were developed and used to measure internal characteristics of the deep narrow microholes with different sizes (i.e., several hundred micrometers) [3]. Samples of this sensor can be purchased from CiS Forschungsinstitut für Mikrosensorik und Photovoltaik GmbH, Erfurt, Germany [4]. Nevertheless, the typical scanning speeds were only $50-100 \mu \mathrm{m} / \mathrm{s}$. So far, the employed silicon tips were uncoated, leading to wear especially at high probing force and speed. Thus, in this work, two more processes were added in the sensor fabrication (i.e., ALD and inductively coupled plasma (ICP) cryogenic dry etching) to deposit conformal protective aluminum oxide $\left(\mathrm{Al}_{2} \mathrm{O}_{3}\right)$ thin-films on the tips. This layer was then additionally used as a mask for shaping the pyramidal tips into micropillars with larger high-aspect-ratio.

\section{Piezoresistive Tactile Cantilever Sensors}

Design and fabrication of the tactile cantilever sensors were determined by the specific requirements of stable and fast probing on deep microholes. Figure 1(a) depicts the fabricated samples of the rectangular cantilever sensors with a dimension of $5000 \times 200 \times 50 \mu \mathrm{m}^{3}$. The used technology was the CiS bulk micromachining process in 4-inch (100)-n-type silicon wafer [4]. The fabrication steps could be classified into four subsequent main processes (i.e., creation of piezoresistive Wheatstone bridge, etching of microprobe tip, metallization of electrical contact, and release of cantilever). Since the sensor production had been 


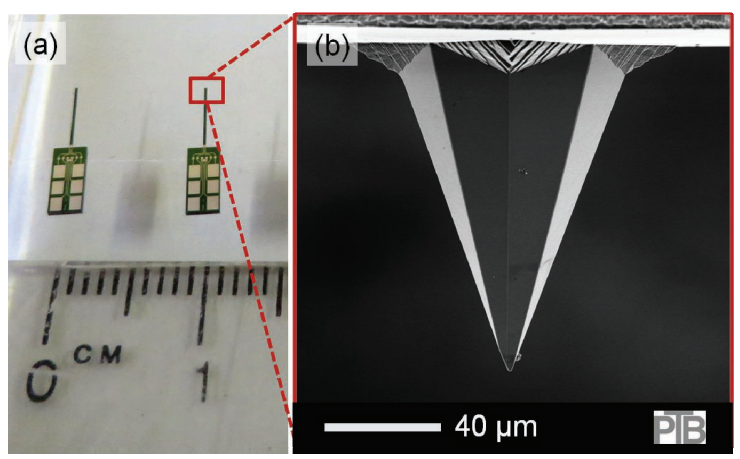

Fig. 1. (a) Fabricated silicon piezoresistive tactile cantilever sensors integrated with (b) a wet-etched microprobe tip.

transferred from laboratory to industry standard, boron implantation process with a concentration of $3 \times 10^{18} \mathrm{~cm}^{-3}$ was used instead of a Borofilm 100 diffusion to integrate $p$-type piezoresistors on area near the cantilever clamped end. As a result, lower offset voltages of $<5 \mathrm{mV} / \mathrm{V}$ could be measured with the realized Wheatstone bridges.

Moreover, to shape the microprobe tips on the backside of the cantilever free end, potassium hydroxide $(\mathrm{KOH})$ wet etching was employed. In this case, the $\mathrm{Si}_{x} \mathrm{~N}_{\mathrm{y}}$ layer of $100 \mathrm{~nm}$ served as a etch mask, which was created with a low pressure chemical vapor deposition (LPCVD) process. The typical bare silicon probing tip obtained by the wet etching process is shown in Fig. 1(b). For having electrical contacts with the piezoresistive strain gauge, aluminum (Al) layers of $800 \mathrm{~nm}$ were deposited on the opened contact holes masked by the thermally grown silicon dioxide $\left(\mathrm{SiO}_{2}\right)$ film of $400 \mathrm{~nm}$. The last key step was free-release of the cantilever using deep reactive ion etching. Thus, a cantilever thickness of $50 \mu \mathrm{m}$ could be achieved.

Being operated in the static contact mode, the cantilever displacement caused by the inducing forces from the rough material surface was converted into an electrical signal using a balanced Wheatstone bridge located close to its clamping to the chip, which was operated with a supply voltage of $1 \mathrm{~V}$. A position-dependent deflection imposed to the tip during surface scanning generates an output signal, which maps the surface profile [5].

\section{Modified High-Aspect-Ratio Wear-Resistant Microprobe Tips}

To further enhance their shape and function, the pyramid-like bare silicon probing tips were then modified to be wear-resistant micropillar tips. Consequently, several further processing steps were developed, which are schematically

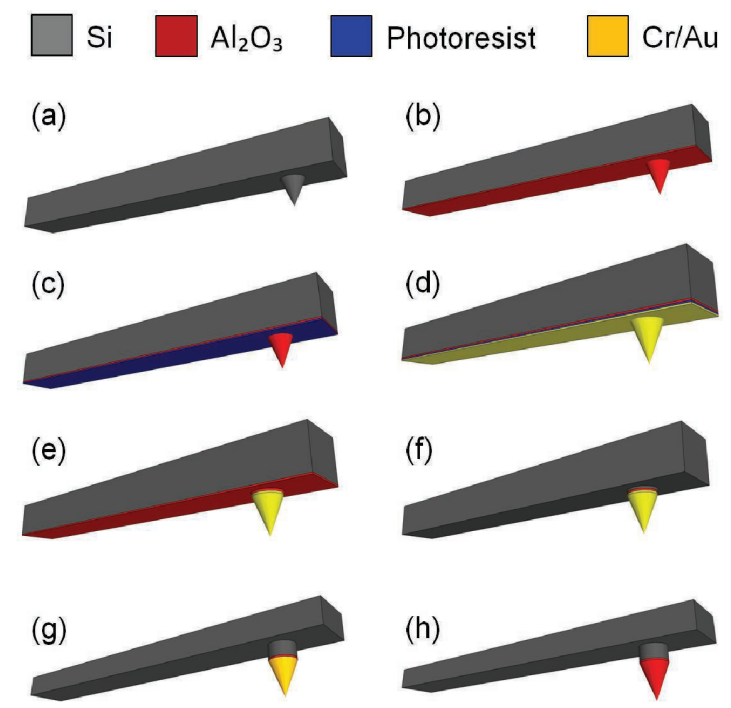

Fig. 2. Schematic of process flow for the fabrication of high-aspect-ratio $\mathrm{Al}_{2} \mathrm{O}_{3}$-coated silicon microprobe tip, including (a) silicon wet etching, (b) $A L D$ of $\mathrm{Al}_{2} \mathrm{O}_{3}$, (c) photoresist coating, (d) Cr/Au masking, (e) $\mathrm{Cr} / \mathrm{Au}$ etching, (f) $\mathrm{Al}_{2} \mathrm{O}_{3}$ removal, (g) ICP cryogenic dry etching, and (h) Cr/Au stripping.

shown in Figs. 2(a-h) with a sectioned piece of the silicon chip viewed from the bottom side. Their details can be described as follows:

(a) After $\mathrm{KOH}$ wet etching process, a sample comprising silicon crystal-dependent micropyramids was cleaned in ultrasonic bath (Bandelin Sonorex TK 52) within 1 min using acetone to remove both organic and inorganic residuals.

(b) Subsequently, a thin conformal wearresistant layer coating of $\mathrm{Al}_{2} \mathrm{O}_{3}$ was deposited on the backside of the sample using atomic layer deposition (ALD). Among thin-film deposition techniques, ALD has the best capability to coat extremely complex $3 D$ shapes with a conformal material layer of high quality [6]. For this purpose, an ALD instrument (SUNALE R200 from Picosun), which is suitable for both plasma and thermal ALD processes, was used to deposit the $\mathrm{Al}_{2} \mathrm{O}_{3}$ thin films. However, because of its higher reliability and better homogeneity, the thermal process was finally chosen considering our previous ALD tests. Deposition was conducted at $160^{\circ} \mathrm{C}$ and $8 \mathrm{hPa}$ in a reactor. Trimethylaluminum (TMA) and $\mathrm{H}_{2} \mathrm{O}$ vapor were used as the aluminum and oxidant sources, respectively. The films of $\mathrm{Al}_{2} \mathrm{O}_{3}$ were formed by following reaction during each cycle:

$2 \mathrm{Al}\left(\mathrm{CH}_{3}\right)_{2}+3 \mathrm{H}_{2} \mathrm{O} \rightarrow \mathrm{Al}_{2} \mathrm{O}_{3}+6 \mathrm{CH}_{4}$. 

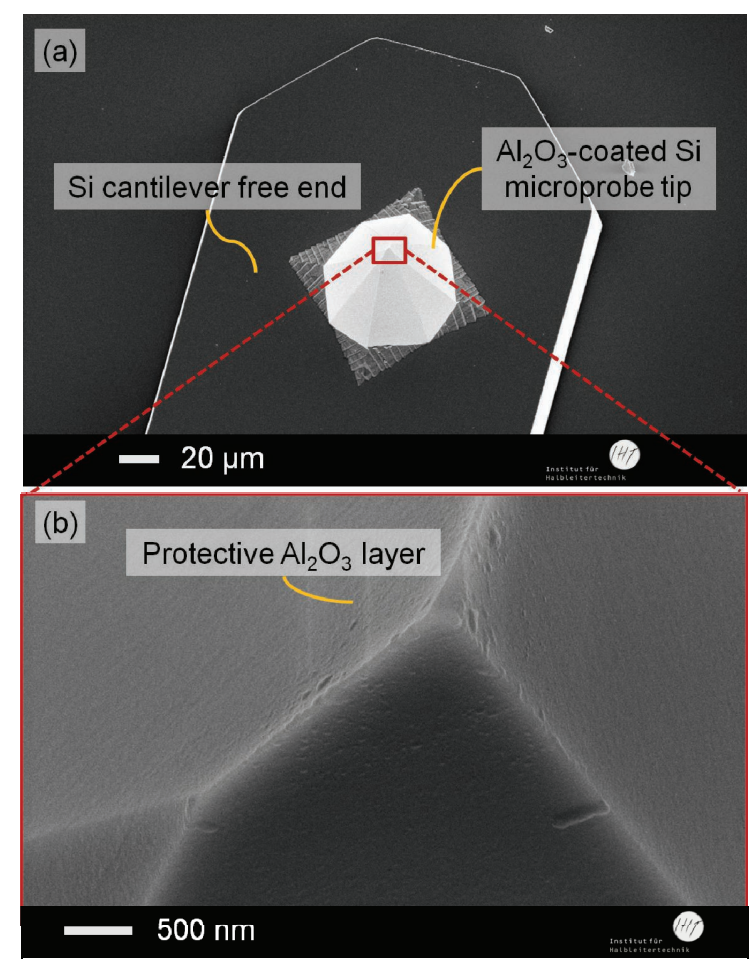

Fig. 3. SEM images of a fabricated (a) silicon microprobe tip on the bottom surface of piezoresistive microcantilever sensor after (b) thin $\mathrm{Al}_{2} \mathrm{O}_{3}$ film coating by $\mathrm{ALD}$.

Pulse and purge durations in each cycle were $0.1 \mathrm{~s} / 6.0 \mathrm{~s}$ and $0.1 \mathrm{~s} / 4.0 \mathrm{~s}$ for TMA and $\mathrm{H}_{2} \mathrm{O}$ vapor, respectively. The growth per cycle (GPC) was determined to be $\sim 0.09 \mathrm{~nm}$. The deposition results are shown in Figs. 3(a) and (b). Besides the roughness of the $\mathrm{Al}_{2} \mathrm{O}_{3}$ films, their thickness was also important to be evaluated. Therefore, a Dektak 3030 (Veeco $\mathrm{GmbH}$ ) surface profiler was utilized to measure the thickness of the layer. The tool equipped with a diamond stylus determines the height of the step (i.e., between the uncoated and coated areas), which was amplified and recorded on a thermosensitive chart paper. Furthermore, to improve its precision, an optical microscope was used to position the sample under stylus. For a quantitative measurement, six samples were observed where each had at least four step values to be measured. The measured thickness of the $\mathrm{Al}_{2} \mathrm{O}_{3}$ layer using this method was $13.79 \pm 1.26 \mathrm{~nm}$ in average. Meanwhile, for the surface roughness measurement, atomic force microscope (AFM) image was captured, which is shown in Fig. 4. A root

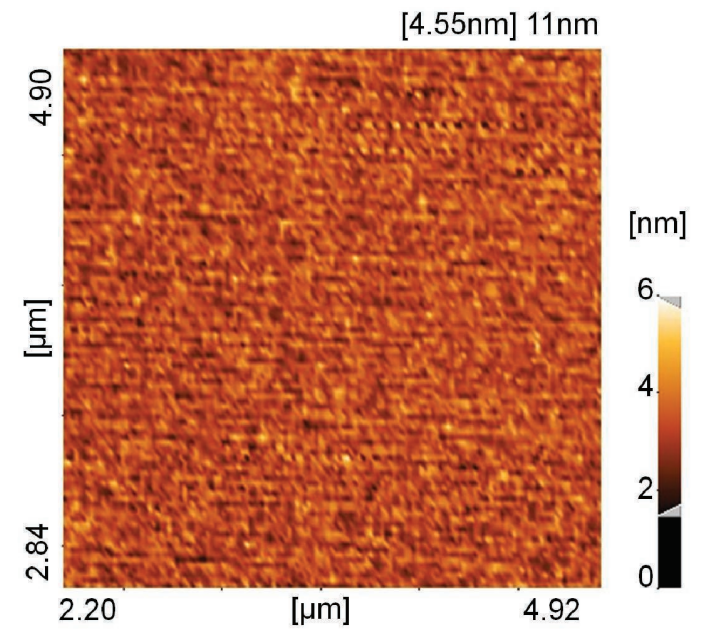

Fig. 4. AFM image of the deposited $\mathrm{Al}_{2} \mathrm{O}_{3}$ layer surface profile.

mean square deviation of $0.65 \mathrm{~nm}$ was found confirming the $\mathrm{Al}_{2} \mathrm{O}_{3}$ surface conformity and quality.

(c) As the protective layer covers all areas on the backside of the sample, it needs then to be etched selectively. In this case, only microprobe tip should be coated with $\mathrm{Al}_{2} \mathrm{O}_{3}$ because having full bi-layer structure of the cantilever beam on one side was unfavorable considering the thermal stress effects that may occur due to different thermal expansion coefficients. Thus, a photoresist layer of Shipley S1818 was spun on it at a rotation speed of $5000 \mathrm{rpm}$ and duration of $35 \mathrm{~s}$. It should be emphasized that using too slow spinning is avoided because the photoresist may overcoat the tips. Moreover, to ensure the free exposed tips from resist, oxygen $\left(\mathrm{O}_{2}\right.$, $10 \mathrm{sccm}$ ) plasma removal treatment (ICP, $500 \mathrm{~W}$ ) was conducted using a 100-E plasma etcher (Technics Plasma $\mathrm{GmbH}$ ) within 2.5 min under room temperature and pressure of $0.5 \mathrm{~Pa}$.

(d) Next, following the opening of photoresist on the micropyramids, chromium/gold $(\mathrm{Cr} / \mathrm{Au}$ ) layers of $30 \mathrm{~nm} / 200 \mathrm{~nm}$ were deposited on the top of the already $\mathrm{A}_{12} \mathrm{O}_{3^{-}}$ coated silicon sample by a customized electron beam physical vapor deposition (EBPVD) machine. They were intended to be used as a sacrificial mask. In this step, a rotation setup of the sample holder had to be used to have homogeneous deposition of the target materials on microtips. 


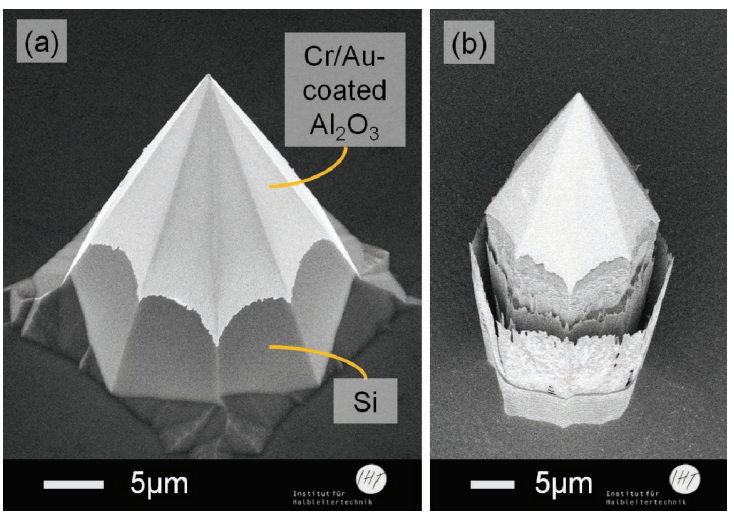

Fig. 5. SEM images of the high-aspect-ratio $\mathrm{Al}_{2} \mathrm{O}_{3}-$ coated silicon microprobe tip after (b) selective $\mathrm{Cr} / \mathrm{Au}$ mask deposition and (b) ICP cryogenic dry etching.

(e) The lift-off process was performed afterwards in an ultrasonic bath using acetone $(f=35 \mathrm{kHz})$. As expected, the $\mathrm{Cr} / \mathrm{Au}$ layers above the $\mathrm{Al}_{2} \mathrm{O}_{3}$-coated silicon substrate floor had been lifted off together with the photoresist. In this case, they only remain on the micropyramids.

(f) Since the $\mathrm{Cr} / \mathrm{Au}$ had been selectively created on the micropyramids and served as a mask, the undesired $\mathrm{Al}_{2} \mathrm{O}_{3}$ layer on the silicon substrate floor could then be etched by using buffered hydrofluoric acid (HF, 5\%) solution inside a small glass within $10 \mathrm{~s}$ and subsequently rinsed with deionized (DI) water. Hence, the boundary between silicon and $\mathrm{Cr} / \mathrm{Au}$-coated $\mathrm{Al}_{2} \mathrm{O}_{3}$ layers on a micropyramid could be clearly distinguished (Fig. 5(a)).

(g) By using an SI 500C cryogenic dry etcher (Sentech Instruments), the patterned silicon sample was etched in two subsequent processes within a total time of $5 \mathrm{~min}$ at an ICP power of $500 \mathrm{~W}$, a temperature of $-95^{\circ} \mathrm{C}$, and a reactor pressure of $1.5 \mathrm{~Pa}$ under $\mathrm{SF}_{6} / \mathrm{O}_{2}$ plasma environment

$\left(\mathrm{SF}_{6}=129 \mathrm{sccm}\right.$,

$\mathrm{O}_{2}=11 \mathrm{sccm}$ ). This process offers some advantages compared to the widely used Bosch process based on $\mathrm{C}_{4} \mathrm{~F}_{8}$ and $\mathrm{SF}_{6}$ (e.g., no requirement of two alternating gases because passivation and etching are done simultaneously, less process complexity because synchronization of the passivation and the etching cycles is not required, clean process because the passivation layer will be removed automatically after etching, and no scalloping sidewall effect) [7-10]. During the ICP cryogenic dry etching process, the metal mask was found to be stable. From the experiments, the etch rate of silicon micropillar using this method can reach up to $\sim 4 \mu \mathrm{m} / \mathrm{min}$. As a comparison, typical etch rates of the anisotropic wet etching using $\mathrm{KOH}$ solution $\left(44 \%, 82^{\circ} \mathrm{C}\right)$ and Bosch dry etching are $\sim 0.7 \mu \mathrm{m} / \mathrm{min}$ [11] and $\sim 2.3 \mu \mathrm{m} / \mathrm{min}$ [8], respectively.

(h) Finally, the $\mathrm{Cr} / \mathrm{Au}$ layers were removed in two different solutions. The Au layer could be stripped off using potassium iodide $(\mathrm{KI})$ solution. The typical used mixtures consisted of $\mathrm{Kl}: \mathrm{I}_{2}: \mathrm{H}_{2} \mathrm{O}=4 \mathrm{~g}: 1 \mathrm{~g}: 40 \mathrm{ml}$. Moreover, at room temperature, the $\mathrm{Au}$ etch rate was found to be around $1 \mu \mathrm{m} / \mathrm{min}$. Thus, etch duration of $45 \mathrm{~s}$ was sufficient in our case to assure the complete $\mathrm{Au}$ removal. Meanwhile, to detach $\mathrm{Cr}$ layer, other etchants were utilized, which were mixtures of ceric ammonium nitrate $\left(\left(\mathrm{NH}_{4}\right)_{2}\left[\mathrm{Ce}\left(\mathrm{NO}_{3}\right)_{6}\right]\right)$ : perchloric acid $\left(\mathrm{HClO}_{4}\right): \mathrm{H}_{2} \mathrm{O}=10.9 \%: 4.25 \%: 84.85$. The required time for removing $20 \mathrm{~nm} \mathrm{Cr}$ layer was $30 \mathrm{~s}$ correponding to an etch rate of around $60 \mathrm{~nm} / \mathrm{min}$.

Using this process sequence, a pillar height extension of $>20 \mu \mathrm{m}$ could be obtained for the already wet-etched micropyramids depending on the duration of ICP dry etching (Fig. 5(b)). Thus, in case of the generated $\mathrm{Al}_{2} \mathrm{O}_{3}$-coated $\mathrm{Si}$ micropyramid pillars with a diameter of $20 \mu \mathrm{m}$, their aspect ratios can be increased up to $>3$. Moreover, due to the incompletely removed mask, it was also found that annular silicon thin walls were also present around the pillars. However, the reason of this phenomenon has not been understood yet. Therefore, further optimization of the tip fabrication process is needed to obtain higher rounded tips for smaller cantilever that can be appropriately used inside microholes with diameters $<100 \mu \mathrm{m}$ and lengths of $>1 \mathrm{~mm}$.

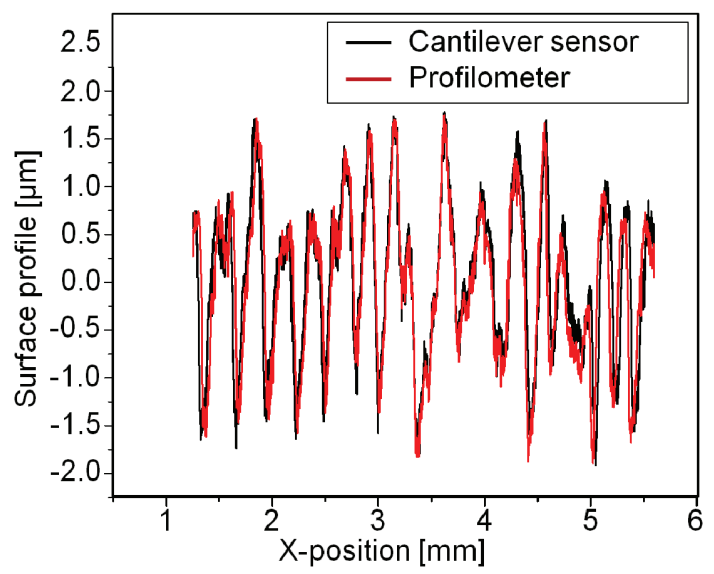

Fig. 6. Performance comparison between the developed cantilever sensor with a speed of $15 \mathrm{~mm} / \mathrm{s}$ and calibrated profilometer. 


\section{Fast Surface Roughness Measurement}

To fulfill a high scanning speed requirement of $>10 \mathrm{~mm} / \mathrm{s}$, which is appropriate to in-line inspection of micro hole machining or drilling processes, wear-protected cantilever probes were successfully tested in 100 fast measurements over a 5-mm-long surface scans on a standard artifact with forces of $60-100 \mu \mathrm{N}$. Its results are in good agreement with those measured with a calibrated profilometer (Fig. 6). The details of this measurement setup had been described in our previous works [3,5]. However, in this current study, the speed of cantilever scanning system was already set to be $15 \mathrm{~mm} / \mathrm{s}$. Regardless of the successful preliminary results, further tests inside a diesel nozzle followed by an investigation of the tip condition are still necessary to be done to evaluate the proposed tactile cantilever sensors.

\section{Conclusion}

Novel designed wear-resistant silicon micropyramid pillars were fabricated by combining bulk micromachining and atomiclayer deposition (ALD) processes. They were integrated on the backside of the piezoresistive cantilever free ends. The protective $\mathrm{Al}_{2} \mathrm{O}_{3}$ coating results were characterized in terms of layer topography, thickness, and roughness using different measurement tools. First fast scanning performance tests of the tactile sensor exhibited promising results in comparison to the calibrated surface profilometer. The optimization of the modified high-aspect-ratio silicon tips is ongoing using the ICP cryogenic dry etching technique. Meanwhile, other protective layers employing different methods of depositions will be used with a subsequent analysis of their surface qualities.

\section{Acknowledgements}

The authors thank Juliane Arens and Doris Rümmler for their technical assistances. This work is performed in the collaborative project "HmtS" funded by the German Federal Ministry of Education and Research (BMBF) under no. VIP0307.

\section{References}

[1] G. Lanza, M. Schlipf, J. Fleischer, Quality assurance for micro manufacturing processes and primary-shaped micro components, Microsystem Technologies 14(12), 1823-1830 (2008); doi: 10.1007/s00542-008-0608-1
[2] H. Murakami, A. Katsuki, T. Sajima, T. Suematsu, Study of a vibrating fiber probing system for 3-D micro-structures: performance improvement, Measurement Science and Technology 25, 094010 (7pp) (2014); doi: 10.1088/09570233/25/9/094010

[3] E. Peiner, L. Doering, Nondestructive evaluation of diesel spray holes using piezoresistive sensors, IEEE Sensors Journal 13(2), 701-708 (2013); doi: 10.1109/JSEN.2012.2225614

[4] CiS Forschungsinstitut für Mikrosensorik und Photovoltaik $\mathrm{GmbH}$, Piezoresistive microprobe, Technical Description (2015), http://www.cismst.org/fileadmin/user upload/publi kationen/cantilever en.pdf

[5] E. Peiner, M. Balke, L. Doering, Slender tactile sensor for contour and roughness measurements within deep and narrow holes, IEEE Sensors Journal 8(12), 1960-1967 (2008); doi: 10.1109/JSEN.2008.2006701

[6] R.L. Puurunen, Surface chemistry of atomic layer deposition: A case study for the trimethylaluminum/water process, Journal of Applied Physics 97, 121301 (2005); doi: 10.1063/1.1940727

[7] R. Abdolvand, F. Ayazi, An advanced reactive ion etching process for very high aspect-ratio submicron wide trenches in silicon, Sensors and Actuators A: Physical 144, 109 - 116 (2008); doi: 10.1016/j.sna.2007.12.026

[8] Y. J. Hung, S. L. Lee, B. J. Thibeault, L. A. Coldren, Fabrication of highly ordered silicon nanowire arrays with controllable sidewall profiles for achieving low-surface reflection, IEEE Journal of Selected Topics in Quantum Electronics 17(4), 869-877 (2011); doi: 10.1109/JSTQE.2010.2068540

[9] Ü. Sökmen, A. Stranz, S. Fündling, S. Merzsch, R. Neumann, H.-H. Wehmann, E. Peiner, A. Waag, Shallow and deep dry etching of silicon using ICP cryogenic reactive ion etching process, Microsystem Technologies 16, 863-870 (2010); doi: 10.1007/s00542-010-1035-7

[10] H.S. Wasisto, S. Merzsch, A. Stranz, A. Waag, E. Uhde, T. Salthammer, E. Peiner, Silicon resonant nanopillar sensors for airborne titanium dioxide engineered nanoparticle mass detection, Sensors and Actuators B: Chemical 189, 146-156 (2013); doi: 10.1016/j.snb.2013.02.053

[11] A. Stranz, Ü. Sökmen, J. Kähler, A. Waag, E. Peiner, Measurements of thermoelectric properties of silicon pillars, Sensors and Actuators A: Physical 171, 48-53 (2011); doi:10.1016/j.sna.2011.01.022 